\title{
DIÁLOGOS ENTRE A TEORIA SOCIAL CRÍTICA HABERMASIANA E A TEORIA FEMINISTA DE NANCY FRASER
}

\author{
Charles Feldhaus ${ }^{1}$ \\ Camila Dutra Pereira ${ }^{2}$
}

\begin{abstract}
Resumo:
Este artigo examina algumas das objeções traçadas por Nancy Fraser à teoria social crítica de Jürgen Habermas à luz de algumas reformulações empreendidas pelo filósofo e sociólogo alemão em Facticidade e validade, quando se devota a aplicar o modelo de democracia deliberativa às demandas feministas por igualdade não apenas de direito, mas também igualdade fática. Em seu artigo Fraser acusa a teoria crítica discursiva não de defender posição abertamente preconceituosas em relação a gênero, mas de uma omissão relativa às questões de gênero, o que, contudo, não deixa de ser censurável. Além do mais, ela defende que o modelo de teoria crítica discursivo dualista baseado na distinção entre as esferas da reprodução social é deficiente no diagnóstico e na identificação de remédios para algumas injustiças sociais sofridas pelas mulheres. $O$ modelo discursivo carece de categorias que permitam interpretar os papéis de gênero e a problemática que envolve a família patriarcal e o trabalho doméstico. O modelo de democracia deliberativa habermasiano demonstra, diferentemente dos textos criticados por Fraser, uma preocupação explicita com as questões de gênero e até mesmo alguma vantagem explicativa em relação ao modelo anterior, mas como tal modelo é construído sobre suposições básicas de A teoria do agir comunicativo, esse modelo ainda encontra dificuldades em enfrentar algumas demandas feministas.
\end{abstract}

Palavras-chave: Teoria social. Reprodução social. Crítica feminista. Juergen Habermas. Nancy Fraser.

\section{DIALOGUE BETWEEN HABERMASIAN'S CRITICAL SOCIAL THEORY AND NANCY FRASER'S FEMINIST THEORY}

\begin{abstract}
:
This article examines some of the objections raised by Nancy Fraser to Jürgen Habermas' critical social theory in light of some reformulations undertaken by the German philosopher and sociologist in Facts and Norms, when he devotes himself to applying the model of deliberative democracy to feminist demands for equality not only of law, but also factual equality. In her article, Fraser accuses critical discursive theory not of defending openly prejudiced positions in relation to gender, but of an omission regarding gender issues, which, however, is still objectionable. Furthermore, she argues that the dualist discursive critical theory model based on the distinction between spheres of social reproduction is deficient in diagnosing and identifying remedies for some social injustices suffered by women. The discursive model lacks categories that allow interpreting gender roles and the problem that involves the patriarchal family and domestic work. The Habermasian model of deliberative democracy demonstrates, unlike the texts criticized by Fraser, an explicit concern with gender issues and even some explanatory advantage over the previous model, but how such model is built on basic assumptions of The Theory of Communicative Action, this model still finds it difficult to face some feminist demands.
\end{abstract}

Keywords: Social Theory. Social Reproduction. Feminist Critics. Juergen Habermas. Nancy Fraser.

1 Doutor em Filosofia pela Universidade Federal de Santa Catarina e pós-doutor em Filosofia pela Martin Luther Universität Halle Wittenberg. Professor Associado da Universidade Estadual de Londrina. Email: charles@uel.br. Orcid: http://orcid.org/0000-0001-6889-0239.

2 Doutoranda em Filosofia pela Universidade Estadual de Londrina - UEL. E-mail: camiladutra.filosofia@uel.br. Orcid: http://orcid.org/0000-0002-1004-8249. 


\section{INTRODUÇÃO}

Juergen Habermas (1929-) é certamente um dos teóricos críticos mais importantes da segunda geração da teoria crítica da sociedade (às vezes também chamada de Escola de Frankfurt). Sua obra já monumental, aborda diferentes temáticas e tópicos, e ele é muito lembrado pela publicação de sua principal obra A teoria da ação comunicativa em 1981. Nessa obra Habermas propõe um novo modelo de teoria crítica da sociedade que pretende entre outras coisas oferecer uma ferramenta de diagnóstico e solução para diversas patologias sociais. As questões relacionadas às injustiças sociais podem ser consideradas como um tipo de patologia social e uma teoria da sociedade que pretenda ser uma alternativa viável as outras versões da teoria crítica da sociedade já existentes deve permitir identificar injustiças sociais assim como apontar remédios para corrigir essas patologias sociais. O modelo habermasiano em A teoria da ação comunicativa se baseia na tese que a dinâmica social se rege pelo binômio sistema e mundo vivido. As patologias sociais seriam, ao menos em parte, resultado da colonização do mundo vivido pelo sistema. $\mathrm{O}$ termo mundo vivido é herdado da fenomenologia de Edmund Husserl e em Habermas se relaciona com os saberes intuitivos e compartilhados, ao passo que o sistema se relaciona com o dinheiro, a burocracia, entre outros. A ideia básica da hipótese da colonização do mundo vivido pelo sistema é que certas esferas da vida humana e da sociedade anteriormente regidas pelo saber do mundo vivido passam gradativamente a ser regidas pelos imperativos sistêmicos do capital e da burocracia, por exemplo e isso gera na política déficits de legitimidade e outros tipos de patologia social. Habermas já havia tentando aplicar uma versão mais embrionária da sua concepção de sociedade como sistema e mundo vivido em sua obra de 1973 A crise de legitimidade do capitalismo tardio. Nessa obra Habermas já busca aplicar as categorias básicas de sua teoria crítica, a fim de explicar as tendências de crise de legitimidade e racionalidade das sociedades capitalistas avançadas. Entretanto, a maneira como a teoria crítica de Habermas identifica as patologias sociais e os remédios para essas patologias não tem agradado a todos e teóricas feministas como a filósofa americana Nancy Fraser (1947-) escreveu um artigo com o sugestivo título O que é crítico na teoria crítica? O caso de Habermas e gênero ${ }^{3}$ em 1985, alguns anos depois da publicação de $A$ teoria da ação comunicativa e pouco mais de uma década da publicação de A crise de legitimidade no

3 O artigo What is critical about critical theory? The case for Habermas and gender, que integra a obra Fortunes of Feminism (2013), foi originalmente publicado em 1985 pela New German Critique. 
capitalismo tardio. Nesse artigo Fraser desafia o potencial crítico da concepção de teoria crítica habermasiana, em especial a capacidade do paradigma discursivo lidar com as patologias sociais relacionadas com as questões feministas. Em particular, a teoria crítica deveria ser capaz de identificar os conflitos envolvidos em diferentes demandas sociais por igualdade, por exemplo, e oferecer remédios adequados. De alguma forma o artigo de Fraser, embora reconheça potencialidades e algumas vantagens no paradigma de discursivo devolvido por Habermas até a publicação de seu artigo em sua versão original de 1985, mas no geral considera que esse paradigma contém algumas deficiências que tornam difícil lidar com as demandas feministas por igualdade na sociedade. É importante observar que com a publicação de Facticidade e validade em 1992 Habermas dedica uma parte do capítulo XI Paradigmas do direito à questão das demandas feministas por igualdade. Dessa maneira, o presente artigo pretende reconstruir as principais críticas de Fraser em seu artigo de 1985 e avaliar se aquilo que Habermas acrescenta ou elucida com sua concepção de democracia deliberativa em 1992 poderia responder ao menos em parte algumas das críticas que Fraser dirige principalmente as obras das décadas anteriores. Como será possível observar, Fraser defende que uma teoria crítica da sociedade deve prestar contas ao fato que a luta feminista estava entre as mais significativas de uma época e deveria lançar luz sobre o caráter e as bases dessa relação de dominação, articulando as patologias e injustiças a fim de superálas. Contudo, como se pretende demonstrar, a análise posterior realizada pelo filósofo e sociólogo alemão, embora muito mais sofisticada que e imune a alguns aspectos da crítica de Fraser ainda não se torna completamente imune a algumas das objeções. Mesmo que Habermas não seja completamente omisso às questões de gênero como foi nas obras anteriores, o modelo discursivo ainda vai encontrar dificuldade em enfrentar alguns tipos de patologias ou injustiças sofridas pelas mulheres apontadas por Fraser que estão relacionadas com a esfera do trabalho não pago do cuidado com os filhos e os demais serviços domésticos que são uma condição essencial da própria dinâmica da sociedade capitalista tardia que Habermas pretendeu atacar com sua obra A crise de legitimidade no capitalismo tardio.

\section{A CONCEPÇÃO DE TEORIA CRÍTICA DE HABERMAS}

\begin{tabular}{|l|l|l|l|l|}
\hline Genista Oialectus & Ano 10 & n. 24 & Setembro - Dezembro 2021 & p. 34 - 53 \\
\hline
\end{tabular}


Em A teoria da ação comunicativa, Habermas vai defender que a "teoria do agir comunicativo não é uma metateoria, mas o início de uma teoria social que se empenha por demonstrar seus parâmetros críticos” (HABERMAS, 2012, p. 9), que trata de um conceito de sociedade em dois níveis “os paradigmas 'mundo da vida' e 'sistema” (HABERMAS, 2012, p. 10) e, que, por sua vez, também "deve possibilitar uma conceitualização do contexto social da vida que se revele adequada aos paradoxos da modernidade" (HABERMAS, 2012, p. 11). Se poderia dizer que o artigo de Fraser pretende exatamente atacar o caráter crítico da teoria discursiva habermasiana, uma vez que ele parece ignorar as questões relativas ao gênero, mostrar as limitações tanto no que diz respeito à capacidade de diagnóstico, quanto à capacidade de fornecer remédios adequados as patologias sociais relacionadas com o gênero, e do mesmo modo a incapacidade do modelo de revelar de maneira completamente adequada os paradoxos das sociedade moderna entre os quais se encontram os conflitos socias por igualdade de tratamento das mulheres na esfera pública da sociedade.

Em 1973, em A crise de legitimidade no capitalismo tardio, Habermas já havia tentado atualizar a teoria crítica da sociedade, especialmente como se poderia pensar uma nova teoria da crise inspirada no pensamento marxista mas que evitasse algumas limitações do pensamento marxista e em reducionismo da teoria dos sistemas. Nessa obra ele traça a distinção entre diferentes tipos de organização social como sociedades primitivas, sociedade tradicional, sociedade capitalista liberal clássica e capitalismo tardio. Ele também problematiza o conceito de crise a partir da perspectiva médica, dramatúrgica e social e tenta mostrar como a sociedade capitalista tardia entra numa espiral de tendência de crises porque o Estado assume funções difíceis de serem cumpridas (FELDHAUS, 2021, p. 145-9). É importante lembrar ao menos os aspectos gerais desse texto aqui porque as críticas de Fraser em boa medida se devotam à insuficiência do paradigma discursivo tal como apresentado nessa obra.

No arcabouço teórico da teoria crítica habermasiana, ele traça uma distinção entre a dimensão simbólica e a dimensão material com aspectos centrais da dinâmica social. O que começou como a distinção entre trabalho e interação em escritos como Técnica e ciência como ideologia em 1968, se transforma com o tempo até chegar em A teoria do agir comunicativo na distinção entre mundo da vida e sistêmica, e a distinção entre ação comunicativa, ação estratégica e ação instrumental. Inicialmente Habermas pretendeu, contra a herança marxista, apontar para a limitação de uma explicação da dinâmica social centrada apenas na dimensão material e sugere a 
inclusão da dimensão da interação ou do simbólico. A distinção entre sistema e mundo da vida pretende explicar as patologias que surgem com o crescimento da racionalidade com relação a fins em diferentes esferas da vida humana. A distinção entre os diferentes tipos de ações pretende sofisticar ainda mais a capacidade de diagnóstico e direcionamento de soluções do paradigma discursivo da teoria crítica. A distinção inicialmente era mais rígida, mas com o tempo Habermas se dirige a uma distinção mais flexivel e que considera muito mais que tipo de ação é predominante como o aspecto mais importante e não a pura e simples presença de um tipo ou outro como evidência de alguma patologia social. Como exemplos de reprodução material é possível indicar o trabalho social e da reprodução simbólica a socialização dos jovens, a consolidação da solidariedade grupal e a transmissão das tradições culturais (cf. HABERMAS, 1986, p. 214). Tal distinção é importante pois Habermas a utiliza para classificar práticas e atividades sociais reais, diferenciadas de acordo com qual das funções servem exclusiva ou principalmente. $\mathrm{O}$ autor preocupa-se com o modo como os imperativos burocráticos do estado administrativo e os valores monetários da economia se intrometem nos contextos do mundo da vida. Em sua concepção, a família é um contexto primordial do mundo da vida, cada vez mais invadido pelas restrições da economia pública e pelos imperativos burocráticos normalizadores.

\section{AS CRÍTICAS DE FRASER À CONCEPÇÃO DE TEORIA CRÍTICA DISCURSIVA DE HABERMAS}

Em $O$ que é crítico na teoria crítica?, Fraser desenvolve um conjunto de objeções à concepção de teoria crítica de Habermas, em particular ela entende que o modelo baseado na dicotomia entre mundo da vida e sistema e que concebe as lutas emancipatórias como lutas contra a colonização do mundo da vida, como fez Habermas, corre-se o risco de apoiar e restabelecer um domínio, não de ação comunicativa livre e igualitária, mas de dominação masculina e subordinação feminina. Para evitar esse perigo, uma teoria crítica não deve colocar a família nuclear e a economia oficial em lados opostos da principal divisão categórica. Assim, as distinções teóricas primárias de Habermas são inadequadas de uma perspectiva feminista em razão do contraste entre integração de sistema e mundo da vida. As inadequações na conceituação regularmente se traduzem em análises empíricas ou diagnósticos de época questionáveis e em categorias que não funcionam como conceitos emancipatórios e úteis para a prática crítica.

\begin{tabular}{|l|l|l|l|l|}
\hline Genista Oialectus & Ano 10 & n. 24 & Setembro - Dezembro 2021 & p. 34 - 53 \\
\hline
\end{tabular}


A distinção traçada por Habermas ao menos até a publicação do artigo de Fraser em 1985 entre reprodução simbólica e material pode ser interpretada de duas maneiras. A primeira assume que as duas funções são "tipos naturais" distintos. As práticas educativas seriam orientadas para a reprodução simbólica e as práticas que produzem alimentos e objetos estariam, por sua natureza essencial, preocupadas com a reprodução material. Já a interpretação "pragmáticacontextual" não classifica as práticas de educação infantil como inerentemente orientadas para a reprodução simbólica. Para Fraser, a interpretação das duas dimensões da dinâmica social como tipos naturais é inadequada, pois "criar filhos não é per se atividade de reprodução simbólica; é igualmente e ao mesmo tempo atividade de reprodução material” (FRASER, 2013 [1985], p. 22). Logo, o tratamento que o capitalismo dá à reprodução social é contraditório, pois apesar de não funcionar sem essa atividade, "confere a ela pouco ou nenhum valor econômico" (FRASER et al, 2019, p. 111). O mesmo raciocínio se aplica às atividades institucionalizadas no trabalho remunerado capitalista moderno, tendo em vista que a produção de alimentos e objetos contribui para a sobrevivência biológica das pessoas, mas também reproduz identidades sociais com significados mediados simbolicamente. Fraser conclui que a distinção entre o trabalho não remunerado das mulheres e outras formas de trabalho do ponto de vista da reprodução não pode ser uma distinção de "tipos naturais", mas uma distinção contextual-pragmática com o propósito de enfocar o que é, em cada caso, apenas um aspecto de um fenômeno de duplo aspecto. Por conseguinte, a classificação dos tipos naturais legitimaria a separação institucional da criação dos filhos do trabalho assalariado e o confinamento das mulheres a uma esfera separada, arranjo institucional que é considerado um dos fundamentos da subordinação das mulheres modernas. Com isso Fraser não está querendo dizer que o arcabouço teórico habermasiano seja explicitamente preconceituoso em relação aos gêneros, mas que a omissão de Habermas em enfrentar o problema de gênero não pode ser considerado como meramente neutra. $\mathrm{O}$ ponto de Fraser consiste muito mais em defender que o aspecto dual das esferas de reprodução social da teoria crítica de Habermas não pode se omitir em relação à questão de gênero sob pena de incorrer no erro que já foi apontado por Simone de Beauvoir no clássico feminista $O$ Segundo Sexo, "a ausência ou a insignificância do elemento feminino no conjunto de uma obra já é sintomática [...]” (BEAUVOIR, 2019, p. 328). Ou seja, a omissão de Habermas está carregada de significado e demonstra algumas deficiências no paradigma discursivo como diagnóstico de época da dinâmica dos movimentos sociais, em especial dos movimentos feministas de luta pela igualdade social e na apresentação de remédios às injustiças 
sofridas pelas mulheres, uma vez que um diagnóstico inadequado pode levar a uma resposta ou a uma solução inadequada. Por isso, o paradigma discursivo, se quiser prestar a devida atenção e oferecer uma resposta adequada às demandas feministas precisa enfrentar a questão de frente e mostrar como o modelo lida com as reivindicações por melhores condições na sociedade. E mesmo que Habermas não tenha feito nenhuma menção explícita ao nome de Fraser em sua obra Facticidade e Validade, o fato é que ele procurou responder explicitamente à questão das demandas feministas por igualdade. Mais adiante trataremos em maior detalhe do que Habermas diz nessa obra.

Fraser examina também a distinção entre "contextos de ação socialmente integrados" e "contextos de ação integrados ao sistema". Os primeiros seriam aqueles em que agentes coordenam suas ações por referência a alguma forma de consenso intersubjetivo sobre normas, valores e fins, baseado no discurso e na interpretação linguística. Já os segundos seriam aqueles em que ações são coordenadas pelo entrelaçamento de consequências não intencionais, enquanto cada ação individual é determinada por cálculos auto interessados e maximizadores de utilidade. Habermas considera o sistema econômico capitalista um caso paradigmático de "contexto de ação integrado ao sistema", e a família nuclear moderna um "contexto de ação socialmente integrado", distinção que Fraser considera abranger seis elementos conceituais: funcionalidade, intencionalidade, linguisticalidade, consensualidade, normatividade e estrategicidade. Tanto no local de trabalho capitalista quanto na família nuclear moderna, as consequências das ações podem ser funcionalmente entrelaçadas de modos não intencionais pelos agentes. Fraser presume que a distinção gira em torno dos elementos de consensualidade, normatividade e estrategicidade e distingue duas interpretações da posição de Habermas: 1) o contraste entre os dois tipos de contextos de ação como diferença absoluta: contextos integrados de sistema não envolvem consensualidade ou referência a normas e valores morais, e contextos socialmente integrados não envolvem cálculo estratégico (cf. HABERMAS, 1984, p. 85); 2) o contraste como diferença de grau: contextos integrados de sistema envolvem alguma consensualidade e referência a valores morais, e contextos socialmente integrados envolvem alguns cálculos estratégicos. Para Fraser, a interpretação das diferenças absolutas é extrema demais para ser útil para a teoria social (cf. FRASER, 2013 [1985], p. 25), pois a família nuclear moderna não é desprovida de cálculos estratégicos individuais. Esses contextos de ação, embora não sejam oficialmente contabilizados como econômicos, possuem dimensão estratégica e econômica. Como a interpretação das

\begin{tabular}{|l|l|l|l|l|}
\hline Q Rovista Dialectus & Ano 10 & n. 24 & Setembro - Dezembro 2021 & p. 34 - 53 \\
\hline
\end{tabular}


diferenças absolutas não distingue a economia capitalista da família nuclear, Fraser infere que a diferença não é de grau, mas uma interação dos três elementos.

A caracterização da família como um domínio de reprodução simbólica, socialmente integrado, e do local de trabalho pago como um domínio de reprodução material integrado ao sistema tende a exagerar as diferenças e ocultar as semelhanças, desviando "[...] a atenção do fato de que o lar, como o local de trabalho remunerado, é um local de trabalho, embora não remunerado e muitas vezes não reconhecido" (FRASER, 2013 [1985], p. 28). Ainda, oculta o fato de que, no local de trabalho remunerado e no lar, as mulheres são designadas para ocupações femininas, voltadas para o serviço, frequentemente sexualizadas e subordinadas aos homens.

Opondo-se às implicações da tese de colonização de Habermas, Fraser reputa que a sociologia dualística de A teoria do agir comunicativo, apesar do potencial crítico embutido nela, ainda deixa de atacar os arranjos tradicionais de gênero que comprometem a igualdade de participação das mulheres na participação política. Aqui é bom lembrar que Fraser também defende um princípio de paridade de participação na esfera pública política para as mulheres, mas suas ferramentas de diagnóstico entendem que as demandas por igualdade se baseiam tanto em aspectos relacionados ao reconhecimento, quanto relacionados à redistribuição e por isso conseguem pontuar melhor onde se encontram as patologias a ser enfrentadas para garantir a paridade de participação politica das mulheres em igualdade de condições na esfera pública política. O modelo discursivo habermasiano fala explicitamente apenas de incluir todos os concernidos pelas normas controversas no debate, mas deixa ao próprio debate identificar e problematizar os aspectos em que alguns membros da sociedade, nesse caso as mulheres, tem mais dificuldade em participar em igualdade de condições do debate. Aqui também é impoprtante lembrar que ao tratar dos direitos culturais em A inclusão do outro, Habermas critica a solução proposta por Charles Taylor de criar uma categoria específica de direitos culturais para enfrentar os problemas relacionados com as identidades culturais e propõe uma reinterpretação dos direitos individuais clássicos para atender as demandas por reconhecimento (FELDHAUS \& SARAIVA, 2017, p. 212-5). A questão da desiguldade de gênero provavelmente não seria resolvida pura e simplesmente com a estratégia proposta por Taylor de criar direitos culturais, mas o ponto é que Habermas não dá muitas dicas de como uma solução do modelo atual baseado nos direitos individuais liberais poderia enfrentar o problema e particularmente como poderia enfrentar o problema da falta de paridade de participação na esfera pública política pelos grupos marginalizados com base em questões culturais. 
Entretanto, Fraser também reconhece que, apesar das dificuldades aventadas, a teoria crítica de Habermas oferece um relato das relações interinstitucionais entre as esferas da vida pública e privada no capitalismo clássico com potencial crítico genuíno. Mas, para realizar esse potencial, é necessário reconstruir o subtexto de gênero não tematizado de seu material. Nesse intuito, Fraser retorna à concepção habermasiana pela qual os sistemas econômicos e estatais estão situados com respeito ao mundo da vida (cf. FRASER, 2013, p. 32). Habermas sustenta que, com a modernização, os sistemas econômicos e estatais não são simplesmente desligados ou desligados do mundo da vida; também devem estar relacionados e incorporados a ele. $\mathrm{O}$ mundo da vida é diferenciado em duas esferas que fornecem ambientes complementares apropriados para os dois sistemas: enquanto a esfera privada ou família nuclear está vinculada ao sistema econômico, a esfera pública ou espaço de participação política, debate e formação de opinião está vinculada ao sistema administrativo estatal. Portanto, a família está ligada à economia por meio de trocas com dinheiro, fornecendo-a força de trabalho socializada em troca de salários, além de demanda para bens e serviços mercantilizados. A explicação habermasiana trata a família nuclear moderna como uma instituição historicamente emergente com suas próprias características positivas e determinadas, que surge concomitantemente com e em relação à economia capitalista emergente, ao estado administrativo e à esfera pública política, traçando algumas das dinâmicas de troca entre essas instituições e indicando como se adaptam às necessidades umas das outras.

Uma teoria social crítica das sociedades capitalistas precisa de categorias sensíveis ao gênero, pois os conceitos de trabalhador, consumidor e salário não são estritamente econômicos, mas "econômicos de gênero". Também o conceito de cidadania não é estritamente político, mas "político-de-gênero". A tese de colonização de Habermas falha em compreender que os canais de influência entre o sistema e as instituições do mundo da vida são multidirecionais, replicando um suporte institucional da subordinação das mulheres: a separação baseada em gênero da economia regulada pelo Estado e a esfera pública dominada pelos homens:

As categorias de Habermas tendem a representar erroneamente as causas e subestimar o escopo do desafio feminista ao capitalismo do estado de bem-estar. As lutas e desejos das mulheres contemporâneas não são adequadamente esclarecidos por uma teoria que traça a linha de batalha básica entre o sistema e as instituições do mundo da vida. Da perspectiva feminista, há uma linha de batalha mais básica entre as formas de dominação masculina que ligam o sistema ao mundo da vida e a nós (FRASER, 2013, p. 50).

\begin{tabular}{|l|l|l|l|l|}
\hline Qevista 2 ialectus & Ano 10 & n. 24 & Setembro - Dezembro 2021 & p. $34-53$ \\
\hline
\end{tabular}


Embora Habermas queira criticar a dominação masculina, suas categorias diagnósticas desviam a atenção para o problema da reificação neutra em relação ao gênero. Apesar disso, o filósofo fez concessões importantes às demandas feministas nas obras posteriores à A teoria do agir comunicativo, não apenas tematizando o papel de gênero da cidadania, mas de alguma forma reconhecendo a cegueira de gênero da formulação original de sua teoria social crítica.

Fraser reconhece que Habermas oferece uma alternativa para as abordagens padrão de separação do público e privado nas sociedades capitalistas, conceituando o problema como uma relação entre quatro termos: família, economia, estado e esfera pública. Sua visão sugere que no capitalismo clássico existem duas separações público-privadas distintas, mas interrelacionadas: uma separação público-privada ao nível dos "sistemas" e a separação público-privada no "mundo da vida", a separação da família, ou esfera privada do mundo da vida, do espaço de formação e participação de opinião política, ou esfera pública do mundo da vida. Os papéis de trabalhador e consumidor vinculam a economia privada e a família privada, enquanto os papéis de cidadão e cliente vinculam o Estado público e as instituições de opinião pública. Apesar do relato sofisticado das relações entre as instituições públicas e privadas nas sociedades capitalistas clássicas, Habermas falha em tematizar o gênero das relações que descreve. Nesse sentido, a luta na história dos movimentos operários/sindicais era por um salário concebido não como pagamento a um indivíduo sem gênero pelo uso da força de trabalho, mas "como pagamento a um homem pelo sustento de sua esposa e filhos economicamente dependentes, legitimando a prática de pagar menos às mulheres por trabalho igual/comparável" (FRASER, 2013, p. 34). Nessa perspectiva, as mulheres não estão ausentes no local de trabalho remunerado: são trabalhadoras de serviço das profissões de ajuda que utilizam habilidades maternas; mal remuneradas, pouco qualificadas e de baixo status em ocupações segregadas por sexo; trabalhadoras em tempo parcial e dupla jornada; esposas e mães que "saem para trabalhar" (cf. PATEMAN, 1985). Essa diferença na qualidade da presença das mulheres no local de trabalho remunerado atestaria a dissonância conceitual entre a feminilidade e o papel da trabalhadora no capitalismo clássico, confirmando o papel masculino do trabalhador.

O outro papel que liga a economia oficial e a família na teoria crítica de Habermas é o de consumidor que, no capitalismo clássico, é companheiro e ajudante do trabalhador. Segundo Couture, "a questão não é que ser consumidor esteja necessariamente ligado a ser mulher [...] nas condições sociais existentes, o papel do consumidor está principalmente associado às mulheres, e 
isso é uma função de uma história questionável de subordinação das atividades femininas a parceiros assalariados" (COUTURE, 1995, p. 265). Por conseguinte, a divisão sexual do trabalho doméstico atribui às mulheres o trabalho não remunerado de comprar e preparar bens e serviços para o consumo doméstico, o que se confirma examinando a história da publicidade de bens de consumo, que interpela seu sujeito, o consumidor, como feminino. A maneira como o paradigma discursivo de Habermas lida com os papéis que ligam a família e a economia é omisso também por não fazer menção ao papel de educador dos filhos, um papel feminino destinado a realizar o trabalho não remunerado de supervisionar a produção da força de trabalho que a família troca por salários. Em função disso, a omissão representa, para Fraser, uma marca de androcentrismo e tem consequências significativas, já que a consideração do papel do educador poderia ter apontado para a relevância central do gênero para a estrutura institucional do capitalismo clássico, e levado à revelação de outros papéis de gênero.

Enfim, o modelo discursivo de Habermas permitiria capturar algo importante sobre a dinâmica intrafamiliar. Contudo, é pouco enfatizado que as ações coordenadas por consenso normativamente garantido na família nuclear chefiada por homens são reguladas pelo poder, sendo um erro restringir o uso do termo "poder" a contextos burocráticos: "os teóricos críticos fariam melhor em distinguir diferentes tipos de poder, por exemplo, o poder patriarcal doméstico, de um lado, e o poder patriarcal-burocrático, do outro" (FRASER, 2013, p. 30). E mesmo essa distinção não basta para tornar a estrutura de Habermas adequada a todas as formas empíricas de dominação masculina nas sociedades modernas, pois o poder normativo-doméstico-patriarcal é apenas um dos elementos que reforçam a subordinação das mulheres na esfera doméstica. Para capturar os demais, seria necessário um arcabouço teórico-social capaz de analisar as famílias também como sistemas econômicos que envolvem a apropriação do trabalho não remunerado das mulheres e se articulam com outros sistemas econômicos que envolvem trabalho remunerado.

\section{UMA RESPOSTA DE HABERMAS ÀS CRÍTICAS FEMINISTAS EM FACTICIDADE E VALIDADE}

Como já dito, com a publicação de Facticidade e validade em 1992 Habermas dedica uma seção inteira do capítulo IX Paradigmas do direito à dialética entre igualdade de fato e igualdade de direito das mulheres. Se lembramos, por exemplo, que a esfera do direito do

\begin{tabular}{|c|c|c|c|c|}
\hline Q & Ano 10 & n. 24 & Setembro - Dezembro 2021 & p. $34-53$ \\
\hline
\end{tabular}


paradigma do reconhecimento de Axel Honneth em Luta por reconhecimento tem como princípio respectivo o princípio da igualdade se poderia facilmente pensar nesse texto como um bom caminho para entender como o paradigma discursivo lida com a dinâmica dos movimentos sociais, em particular a dinâmica dos movimentos feministas. A estratégia de solução do paradigma discursivo para a dialética entre igualdade de direito e igualdade de fato é envolver os concernidos "na percepção, articulação e imposição organizada de seus próprios interesses" (HABERMAS, 2020, p. 519) e dessa maneira os concernidos ou afetados pela norma controversa sobre alguma discriminação de gênero se tornam participantes eles mesmos "da construção do contrapoder e da articulação dos interesses sociais" (HABERMAS, 2020, p. 519). A ideia básica de Habermas é que os concernidos não podem ser entendidos apenas como destinatários das normas e regulamentações especiais que tem a ver com os seus interesses, mas devem ser eles mesmos participantes ativos no espaço público da construção da solução ou da regulamentação ao problema de discriminação de gênero identificado e com isso se consegue "reforçar o status jurídico positivo do indivíduo" (HABERMAS, 2020, p. 519). O caminho proposto é estabelecer "modos de formação cooperativa da vontade" (HABERMAS, 2020, p. 520) e no caso específico das demandas feministas por igualdade no mercado de trabalho, que é uma das demandas abordados por Habermas nesse texto, a solução consiste em "pôr à disposição procedimentos e formas de organização que capacitem os participantes a resolverem suas questões e seus conflitos" (HABERMAS, 2020, p. 520). Os exemplos propostos são mecanismos de autogestão e instâncias de arbitragem, a fim de evitar que as leis e convenções coletivas levem à colonização do comportamento dos trabalhadores (HABERMAS, 2020, p. 522), nesse caso das trabalhadoras. O problema da solução habermasiana é que interpreta apenas como patologias ou como discriminações aquelas situações em que o aparato Estatal formal é "insensível às limitações da liberdade resultantes de desigualdades factuais" e quando o aparato Estatal "negligencia restrições à liberdade resultantes das compensações estatais a essas mesmas desigualdades" (HABERMAS, 2020, p. 527). É verdade que Habermas faz importantes apontamentos favoráveis à pauta feminista nesse texto, reconhecendo que a igualdade de tratamento entre gêneros "não pode ser entendida apenas como concessões do Estado social no sentido da partilha justa de bens sociais" (HABERMAS, 2020, p. 530), o que parece abrir espaço para um enfrentamento das questões de gênero tanto na dimensão cultural quanto na dimensão redistributiva como advoga Fraser. Assim como Fraser ele também foca na participação mais ativa das mulheres na esfera política como parte da solução do problema 
da desigualdade fática e parece inclusive abrir alguma perspectiva para o que tem sido chamado da interseccionalidade, de uma interrelação entre demandas feministas com demandas raciais, econômicas, entre outras. Embora Habermas não empregue o termo ele critica as classificações sobregeneralizantes acerca das situações dos membros discriminados da sociedade, nesse caso das mulheres, e diz que "com frequência, aquilo que parece promover a igualdade das mulheres em geral favorece somente uma determinada categoria de mulheres (já privilegiadas) em detrimento das demais" (HABERMAS, 2020, p. 534). A razão para isso está exatamente no ponto central das defensoras do feminismo decolonial e da interseccionalidade. As desigualdades de gênero geralmente são sobrepostas por outros tipos de desigualdade social. Não por acaso Fraser juntamente com outras pensadoras feministas publicou um livro em 2019 com o título de Feminismo para os $99 \%$ Um manifesto, em que ela chama a atenção para necessidade de superação da divisão dentro da pauta feminista das demandas por identidades e das demandas por redistribuição. O feminismo precisa atacar o capitalismo e particularmente o trabalho não remunerado das mulheres na esfera doméstica, mas também não pode esquecer de outras dimensões da discriminação como ração, etnia, classe social, entre outras. A interseccionalidade, por sua vez, é uma ferramenta analítica empregada para resolver problemas resultantes de divisões sociais baseadas em relações de poder vinculadas à classe, raça, gênero, etnia, orientação sexual, etc (COLLINS \& BILGE, 2021, p. 16) que são muitas vezes ignoradas por abordagens focadas apenas na política da identidade ou na política da redistribuição e Habermas parece reconhecer, embora não desenvolva esse aspecto em Facticidade e validade, quando diz que "as desigualdades específicas de gênero se correlacionam de forma complexa e não evidente com prejuízos de outro tipo (ligados à origem social, idade, etnia, orientação sexual, etc)” (HABERMAS, 2020, p. 534). O problema do modelo habermasiano é não oferecer recursos muito claros a respeito de como enfrentar esse tipo de problemas e se restringir apenas a reconhecer a existência do problema quando afirma que "a legislação e a justiça [que] se orientam por padrões de interpretação tradicionais, (...) fortalece [m] os estereótipos vigentes da identidade de gênero" (HABERMAS, 2020, p. 535).

Além disso, é preciso lembrar contra a objeção da interpretação das distinções como tipos naturais que a distinção entre ação comunicativa e estratégica nas primeiras obras de Habermas era realizada de maneira mais estrita e ele estava comprometido com ações estratégicas veladas, que ele chamava de comunicação sistematicamente distorcida. Com o passar do tempo, 
Habermas abandona esse conceito e torna a distinção mais dinâmica, indo em direção a uma distinção em termos de grau, em que ações sociais têm aspectos estratégicos e comunicativos e abandonando a ideia da existência de tipos puros. A questão é saber qual predomina em certo momento se a estratégica, se a comunicativa, a fim de determinar o caráter patológico ou não de um aspecto da sociedade ou outro. Com essa flexibilização da distinção entre tipos de ação, se poderia dizer que Habermas estaria tentando evitar o tipo de críticas que Fraser faz a interpretação dos tipos naturais e os problemas que esse tipo de distinção rígida pode acarretar.

\section{REAVALIANDO A POSIÇÃO DE HABERMAS}

A discussão das demandas feministas, em Facticidade e validade (2020 [1992]), XI Paradigmas do direito, por igualdade trata da aplicação do paradigma jurídico desenvolvido principalmente no segundo e terceiro capítulo da obra Facticidade e validade, que tratam especificiamente da reconstrução do sistema de direitos moderno e por isso a questão das demandas feministas servem como um teste do modelo normativo anteriormente apresentado, uma vez que Habermas vai defender que o paradigma discursivo é superior no potencial explicativo e solucionador de problemas aos paradigmas liberal e do Estado de bem-estar social. Nesse sentido, Habermas fundamenta que os direitos somente podem autorizar as mulheres a uma configuração autônoma e privada da vida na medida em que possibilitarem uma participação, em igualdade de direitos, na prática da autodeterminação de cidadãos. Para o filósofo, apenas os envolvidos são capazes de esclarecer os pontos de vista relevantes em termos de igualdade e desigualdade, sob pena de oprimir as vozes capazes de enunciar as razões relevantes para a igualdade ou desigualdade de tratamento. Desse modo, Habermas ampliou a discussão feminista desde a publicação de $A$ teoria do agir comunicativo, adotando uma perspectiva mais abrangente sobre as reivindicações sociais e analisando as razões pelas quais muitas dessas pretensões ainda não foram satisfeitas. Contudo, tendo em vista as críticas de Fraser, falta na análise de Habermas, mesmo naquela de Facticidade e Validade o reconhecimento de que o trabalho de criação dos filhos, feito gratuitamente pelas mulheres, é um pressuposto do capitalismo, que relega o trabalho feminino a um papel menor e desvantajoso socialmente. Portanto, não se trata apenas de identificar a desigualdade entre os sexos, mas de entender a gênese da opressão, os motivos de sua manutenção e as consequências sociais da falta de reconhecimento do trabalho das mulheres. A teoria social 
crítica de Habermas, a esse respeito, permanece incapaz de vislumbrar a problemática em toda sua complexidade, tendo em vista o dualismo categorial que separa o sistema e as instituições do mundo da vida.

Além disso, apesar de Habermas ter se manifestado sobre o aspecto militar da cidadania, ele ainda falha em entender como o local de trabalho capitalista está ligado à família nuclear moderna, ignorando: 1) como o Estado está vinculado à esfera pública do discurso político; 2) como o papel de cidadão-soldado-protetor masculino vincula o Estado e a esfera pública um ao outro, à família e ao local de trabalho remunerado; 3) como o papel de cidadão masculino vincula o Estado e a esfera pública um ao outro e à família e à economia oficial; 5) como o papel masculino de provedor de sustento vincula a família e a economia oficial uma à outra e ao estado e à esfera pública política; 6) como o papel de educador feminino vincula as instituições, supervisionando a construção dos sujeitos necessários para os papéis no capitalismo clássico: “a identidade de gênero feminina e masculina perpassa como fios rosa e azul pelas áreas de trabalho remunerado, administração estatal e cidadania, bem como pelo domínio das relações familiares e sexuais" (FRASER, 2013, p. 38) e Habermas continuou omisso sobre esses pontos.

Enfim, mesmo que Habermas tenha adicionado alguns elementos na obra de 1992, a fim de lidar de maneira mais adequada com as críticas feministas, ainda permanece alguns problemas na concepção teoria crítica e no modelo de democracia deliberativa para atender algumas objeções feministas. Em Further Reflections on the Public Sphere (1992a), concede que: a) "a crescente literatura feminista sensibilizou nossa consciência para o caráter patriarcal da própria esfera pública" (HABERMAS, 1992a, p. 427); b) os ganhos em direitos democráticos e as compensações do estado de bem-estar "ocorreram sem afetar o caráter patriarcal da sociedade como um todo" (HABERMAS, 1992a, p. 428); e, c) "era muito pessimista sobre o poder de resistência e, acima de tudo, o potencial crítico de um público de massa pluralista e internamente muito diferenciado, cujos usos culturais começaram a sacudir as restrições de classe" (HABERMAS, 1992a, p. 438). É notável, ainda, ter o filósofo reconhecido que "a exclusão das mulheres foi constitutiva para a esfera pública política não apenas porque esta foi dominada pelos homens como uma questão de contingência, mas também porque sua estrutura e relação com a esfera privada foram determinadas em um gênero específico" (HABERMAS, 1992a, p. 428).

Apesar de ter deixado muito mais claro como sua visão pode lidar com algunas demandas feministas, a teoria do direito de Facticidade e validade ainda opera com algumas 
suposições de A teoria do agir comunicativo que tem dificuldade de enfrentar as demandas feministas. Como por exemplo, o contraste entre sistema e mundo da vida e a tese da colonização do mundo da vida e a própria concepção de esfera pública. Couture, em sua análise sobre o tema, enfatiza que a consciência de Habermas sobre a autotransformação em seu próprio discurso "[...] constitui um obstáculo para aceitar reclamações" (COUTURE, 1995, p. 271) mesmo na versão aprimorada, de tal maneira que a discussão ainda permanece muito abstrata e com isso ainda permanece incapaz de atender devidamente as reivindicações de gênero. Apesar de Habermas concordar que é necessário que as condições sociais permitam a participação livre e igual de todos os envolvidos, em seu relato essas condições são entendidas como procedimentais ou normativas, e pouco ou nada ainda é dito sobre como garantir as condições de participação igualitária das mulheres concernidas no debate a respeito dos seus próprios interesses. Além disso, Habermas não faz referência alguma às características que as feministas afirmam serem necessárias para fazer as mulheres se sentirem livres para debater em sociedades historicamente dominadas por homens, deixando de fornecer qualquer orientação a respeito da configuração adequada dos direitos especiais para as mulheres que garantam a elas igualdade de participação política. Como elucida Couture, é como se Habermas “[...] não percebesse as inibições específicas que as mulheres enfrentam em discussões públicas, ou talvez não quisesse parecer paternalista" (COUTURE, 1995, p. 272). Em que pese Fraser tenha requerido à Habermas que fosse mais específico sobre as condições sociais e econômicas para a participação efetiva em uma esfera pública não excludente e democrática, a resposta do filósofo "se esquiva da questão de gênero e argumenta que o capitalismo deve ser reformado por meio de várias pressões públicas (mas sem revolução)" (COUTURE, 1995, p. 272). Conforme Couture, o problema da teoria crítica de Habermas é que:

Seu ponto é sobre a legitimidade das razões em geral, e que os argumentos das críticas feministas não são legítimos apenas porque são mulheres falando pelas mulheres primeiro, mas porque apelam a tipos de razões que todos deveriam concordar que são corretas. Habermas não precisa negar as contribuições que as feministas fizeram ao mudar o foco para as relações sexuais e a divisão do trabalho por gênero. Ele apenas nega que tenham inventado um novo tipo de legitimidade ao apelar para suas experiências particulares de opressão, pois isso implicaria que sua teoria unificada da razão e da legitimidade discorresse sobre diferenças que refletem a instabilidade do próprio processo de argumentação (COUTURE, 1995, P. 273).

Em síntese, embora as experiências das mulheres com o processo liberal de discussão pública sejam únicas, Habermas tende a afirmar que a legitimidade de qualquer demanda social se

\begin{tabular}{|l|l|l|l|l|}
\hline Qevista Dialectus & Ano 10 & n. 24 & Setembro - Dezembro 2021 & p. 34 - 53 \\
\hline
\end{tabular}


basearia no princípio universal de incluir todos na discussão e dá a entender que isso poderia ser suficiente como um exigência de justiça social. Dessa maneira, alguns aspectos do relato inicial de Habermas sobre os potenciais críticos da esfera pública burguesa podem oferecer insights úteis sobre o significado emancipatório deste desenvolvimento moderno. Entretanto, a masculinidade e as posições de classe dos participantes não eram incidentais ao modo de interação sustentado pela esfera pública burguesa.

Além disso, a estratégia da descolonização do mundo vivido oriunda do modelo de teoria crítica de A teoria do agir comunicativo que serve de base a reconstrução do sistema de direitos moderno de Facticidade e validade sugere um programa que visa a ressurreição dos modos comunicativos convencionais de interação contra o impacto alienante dos imperativos do sistema, fazendo com que sua formulação do poder emancipatório da razão continue a ser marcada por uma ideologia de gênero. Marie Fleming endossa esta avaliação das ideologias sexistas que sustentam a tese da colonização. Por conseguinte, a descrição de Habermas das consequências patológicas da penetração dos imperativos estratégicos na dinâmica interna do mundo da vida é "conservadora na medida em que funciona em um argumento para a resistência à mudança fundamental no nível das estruturas familiares" (FLEMING, 1997, p. 3-4). A autora concorda com Fraser ao supor que o impulso crítico da tese da colonização repousa sobre um retrato idealizado da vida doméstica em que a integração social deve ser assegurada por meio de processos de comunicação, fazendo com que a tese da colonização reproduza uma ideologia de gênero repressiva.

Conforme Fraser (2013, p. 37), há ainda outro aspecto da cidadania não discutido por Habermas ao menos até a publicação de Facticidade e validade que também está ligado à masculinidade: o aspecto militar da cidadania, isto é, a concepção do cidadão como defensor da política e protetor dos que supostamente não podem se proteger. Stiehm argumenta que a divisão entre homens protetores e mulheres protegidas introduz mais dissonância na relação das mulheres com a cidadania (cf. STIEHM, 1983), confirmando o gênero do papel do cidadão no capitalismo clássico. Nessa perspectiva, os vínculos são forjados pela identidade de gênero masculina, e não por meio de um poder gênero-neutro. Como já dito, em sua obra posterior Habermas (2020, p. 5356) discute o problema do serviço militar não obrigatório para as mulheres e reconhece que ele tem “as implicações simbólicas da exclusão das mulheres do serviço militar" e que isso coloca dúvidas na sociedade se elas podem "reivindicar o mesmo respeito que os homens em seu papel de cidadãos", uma vez que isso gera "estereótipos de gênero" e com isso "as mulheres se verão

\begin{tabular}{l|l|l|l|} 
Ano 10 & n. 24 & Setembro - Dezembro 2021 & p. 34 - 53
\end{tabular}


forçadas pelas regulações compensatórias a se adaptar a instituições que as discriminam estruturalmente" (HABERMAS, 2020, p 536). A solução proposta por Habermas passa novamente pela inclusão das concernidas na esfera pública política e pela suposição de um conceito de gênero como construção social e não como um fato dado. Diz ele que as identidades de gênero assim como as relações entre eles "são construções sociais que se cristalizam ao redor de diferenças biológicas, mas que variam historicamente" (HABERMAS, 2020, p. 539) e aqui novamente é o problema está em não apresentar um critério muito claro para diferenciar entre identidades e relações que poderiam ser aceitáveis e as que não poderiam ser aceitáveis, tudo é deixado ao debate político em que a participação das mulheres historicamente se orientam por uma relação de assimetria e apenas dizer que é uma construção e tem uma história não parece oferecer uma maneira muito clara de como se resolver o problema.

\section{CONSIDERAÇÕES FINAIS}

Como foi possível observar, Habermas desenvolve uma concepção de teoria crítica da sociedade, cujo caráter crítico é desafiado por Fraser exatamente porque seria incapaz de diagnosticar de maneira adequada as patologias sociais relacionadas às demandas feministas e por conseguinte de oferecer remédios apropriados. Fraser sustenta que a concepção de sociedade dual formada pela interação entre sistema e mundo vivido e a tese correlacionada da colonização do mundo vivido é incapaz de identificar adequadamente as patologias sociais relacionadas ao gênero, que a distinção entre a dimensão simbólica e material como categorias rígidas deixa de capturar certos aspectos importantes das injustiças sociais sofridas pelas mulheres como o trabalho doméstico não remunerado. A crítica habermasiana do clientelismo ignora que esse papel é costumeiramente vinculado à figura feminina na família nuclear tradicional, que Habermas insiste em não se posicionar criticamente contra, e nessa visão o homem geralmente tem o papel de provedor e a mulher de consumidora e o modelo discursivo não parece ter muito a dizer contra isso. Em 1992 Habermas oferece alguns complementos ao seu modelo através da imersão na categoria do direito moderno e seu modelo de democracia deliberativa em Facticidade e validade, não obstante, a nova formulação, mesmo apresentando melhoras notórias em relação ao modelo de A crise de legitimidade no capitalismo tardio e A teoria do agir comunicativo ainda permanece suscetíveis a algumas objeções feministas, particularmente no que diz respeito à concepção de

\begin{tabular}{|l|l|l|l|l|}
\hline Rovista Dialectus & Ano 10 & n. 24 & Setembro - Dezembro 2021 & p. 34-53 \\
\hline
\end{tabular}


esfera pública burguesa e por não oferecer recursos para atacar as injustiças relacionadas com o trabalho doméstico não remunerado. É importante notar que essa última formulação da teoria crítica aponta para desenvolvimentos interessantes do modelo discursivo, uma vez que chama a atenção para a interseccionalidade entre diferentes discriminações como raça, etnia, orientação sexual, gênero, etc; mas Habermas ainda diz muito pouco a respeito de como enfrentar essa interseccionalidade se restringindo a propor um debate na esfera pública o mais inclusivo possível, sem considerar que concretamente as condições de participar do discurso ainda são bastante assimétricas tanto no que diz respeito ao gênero quanto a outros tipos de discriminações.

\section{REFERÊNCIAS}

BEAUVOIR, Simone de. O Segundo Sexo: fatos e mitos. 5. ed. Trad. Sérgio Milliet. Rio de Janeiro: Editora Nova Fronteira, 2019.

COLLINS, Patricia Hill \& BILGE, Sirma. Interseccionalidade. Tradução de Rane Souza. São Paulo: Boitempo, 2021.

COUTURE, Tony. Feminist Criticisms of Habermas's Ethics and Politics. In: Dialogue, 34, v. 2, pp. 259-280, 1995.

FELDHAUS, Charles \& SARAIVA, Juliana Marques. As demandas por reconhecimento em Jurgen Habermas e Axel Honneth. In: LIMA, Clóvis Ricardo Monteiro de. Anais do XIII Colóquio Habermas e IV Colóquio de Filosofia da Informação, Rio de Janeiro: Salute, 2017, pp. 207-216.

FELDHAUS, Charles. Crise de legitimidade e pandemia em Habermas. In: LIMA, Clóvis Ricardo Monteiro de. Anais do XVII Colóquio Habermas e VIII Colóquio de Filosofia da Informação, Rio de Janeiro: Salute, 2021, pp. 142-156.

FLEMING, Marie. Emancipation and Illusion: Rationality and Gender in Habermas' Theory of Modernity. Pennsylvania: Pennsylvania State University Press, 1997.

FRASER, Nancy. Unruly Practices: Power, Discourse and Gender in Contemporary Social Theory. Minneapolis: University of Minnesota Press, 1989.

FRASER, Nancy. Rethinking the Public Sphere: A Contribution to the Critique of Actually Existing Democracy. In: Habermas and the Public Sphere. Mass.: The MIT Press, 1992.

FRASER, Nancy. Fortunes of feminism: from state-managed capitalism to neoliberal crisis and beyond. Nova York: Verso, 2013.

\begin{tabular}{|l|l|l|l|l|}
\hline Qovista Dialectus & Ano 10 & n. 24 & Setembro - Dezembro 2021 & p. 34-53 \\
\hline
\end{tabular}


FRASER, Nancy; ARRUZZA, Cinzia; BHATTACHARYA, Tithi. Feminismo para os 99\%: um manifesto. São Paulo: Boi Tempo, 2019.

HABERMAS, Jürgen. Further Reflections on the Public Sphere. In: Habermas and the Public Sphere. Edited by Craig Calhoun. Cambridge, MA: MIT Press, 1992a.

HABERMAS, Jurgen. Técnica e ciência como ideologia. Tradução de Artur Morão. Lisboa: Edições 70, 2006.

HABERMAS, Jurgen. Mudança estrutural da esfera pública. Investigação quanto a uma categoria da sociedade burguesa. Tradução de Flávio R. Kothe. Rio de Janeiro: Tempo brasileiro, 1984.

HABERMAS, Jurgen. A crise de legitimação no capitalismo tardio. Tradução de Vamireh Chacon. Rio de Janeiro: Edições Tempo Brasileiro, 2002.

HABERMAS, Jurgen. A inclusão do outro. Estudos de teoria política. Tradução de Denilson Luís Werle. São Paulo: Editora Unesp, 2018.

HABERMAS, Jurgen. Facticidade e Validade. Contribuições para uma teoria discursiva do direito e da democracia. Tradução de Felipe Gonçalves e Rúrion Melo. São Paulo: Editora

HABERMAS, Jürgen. Ética do Discurso. Obras Escolhidas de Jürgen Habermas. vol. 3. Lisboa: Edições 70, 2014.

HONNETH, Axel. Luta por reconhecimento. A gramática moral dos conflitos sociais. Tradução de Luiz Repa. São Paulo: Editora 34, 2009.

PATEMAN, Carole. The Personal and the Political: Can Citizenship Be Democratic? Lecture III of Women and Democratic Citizenship. In: The Jefferson Memorial Lectures. Berkeley: University of California, 1985.

STIEHM, Judith H. The Protected, the Protector, the Defender. In: Women and Men's Wars, New York: Pergamon Press, 1983.

THORNE, Barrie; YALOM, Marilyn (eds.). Rethinking the Family: Some Feminist Questions. New York and London: Longman, 1982.

\begin{tabular}{|l|l|l|l|l|}
\hline Qenista Dialectus & Ano 10 & n. 24 & Setembro - Dezembro 2021 & p. 34 - 53 \\
\hline
\end{tabular}

